\title{
A Rare Case of Extra-abdominal Desmoid Fibromatosis of the Mandible in a 9-Year-Old Child
}

\author{
Medhini Madi ${ }^{1, \bullet}$ Supriya Bhat ${ }^{2, \bullet}$ Ananya Madiyal2,e \\ ${ }^{1}$ Manipal College of Dental Sciences, Manipal Academy of Higher \\ Education, Manipal, India \\ ${ }^{2}$ A.B. Shetty Memorial Institute of Dental Sciences, Nitte (Deemed \\ to be) University, Deralakatte, Mangalore, Karnataka, India
}

\author{
Subhas G. Babu²,®
}

J Health Allied Sci ${ }^{\mathrm{NU}}$ 2021;11:199-200.

\begin{abstract}
Address for correspondence Supriya Bhat, MDS, Department of Oral Medicine and Radiology, A.B. Shetty Memorial Institute of Dental Sciences, Nitte (Deemed to be) University, Deralakatte, Mangalore, Karnataka 575018, India

(e-mail: dr.supriyabhat@gmail.com).
\end{abstract}

\author{
Abstract \\ Keywords \\ - desmoid fibromatosis \\ - extra-abdominal \\ - benign tumor
}

Desmoid tumors are tumors of the fibrous tissue that are benign, which most commonly occur in the abdominal walls of females who are of childbearing age. The most common location for extra-abdominal desmoid tumors is the shoulder and the upper limb. They show no tendency for metastasis but are locally very aggressive. Here we report a rare case of extra-abdominal desmoid fibromatosis in the mandible of a child.

\section{Introduction}

Desmoid tumors are tumors of the fibrous tissue that are benign. These tumors most commonly occur in the abdominal walls of females who are of childbearing age. The most common location for extra-abdominal desmoid tumors is the shoulder and the upper limb. These are benign tumors showing no tendency for metastasis but are locally very aggressive. ${ }^{1}$ Here we report a rare case of extra-abdominal desmoid fibromatosis in the mandible of a child.

\section{Case Report}

A 9-year-old boy reported to the department of oral medicine and radiology with a complaint of inability to open his mouth since 3 months. Information regarding the complaint and history was given by the parent. History revealed that the patient had a fall from a water tank 3 months ago. Around 4 days after the fall the patient had reduced mouth opening. Approximately 8 days after the fall the patient could open his mouth very little due to which he could not consume solid food. The patient had no associated pain. The patient visited the local hospital wherein FNAC (fine needle aspiration cytology) was done which suggested spindle cell carcinoma. The patient then visited another hospital where he was taken up for biopsy under general anesthesia, but due to the nonavailability of pediatric fiber-optic endoscopy, intubation was not possible. The patient was then referred to our hospital for further management.

On extraoral examination facial asymmetry was detected in the left angle of the mandible. A diffuse, solitary swelling was seen on the left side of the face at the region of the left angle of the mandible, measuring approximately $3 \mathrm{~cm} \times 3 \mathrm{~cm}$ in dimension, extending superiorly $1 \mathrm{~cm}$ above the angle of the mandible, inferiorly $3 \mathrm{~cm}$ below the lower border of the mandible, medially $5 \mathrm{~cm}$ away and below the midline below the chin, and laterally up to the angle of the mandible. On palpation, the swelling was bony hard in consistency with regular borders. There was no evidence of surface ulceration or discharge. The lesion was nontender. There was no evidence of any change in overlying skin color. Trismus was present. The mouth opening was found to be 3 to $4 \mathrm{~mm}$. The left submandibular lymph node was palpable. It was solitary, nontender, mobile, oval in shape, firm in consistency, and roughly measuring around $0.5 \mathrm{~cm} \times 0.5$ $\mathrm{cm}$ with well-defined margins. A panoramic image revealed the presence of a multilocular radiolucency in the angle of the mandible on the left side with evidence of destruction of the lower border of the mandible and the ascending ramus ( $\mathbf{- F i g . 1} \mathbf{1}$ ).

\section{published online February 13, 2021}

DOI https://doi.org/

10.1055/s-0041-1724136 ISSN 2582-4287.

\footnotetext{
(C) 2021. Nitte (Deemed to be University).

This is an open access article published by Thieme under the terms of the Creative Commons Attribution-NonDerivative-NonCommercial-License, permitting copying and reproduction so long as the original work is given appropriate credit. Contents may not be used for commercial purposes, or adapted, remixed, transformed or built upon. (https://creativecommons.org/licenses/by-nc-nd/4.0/).

Thieme Medical and Scientific Publishers Pvt. Ltd. A-12, 2nd Floor, Sector 2, Noida-201301 UP, India
} 


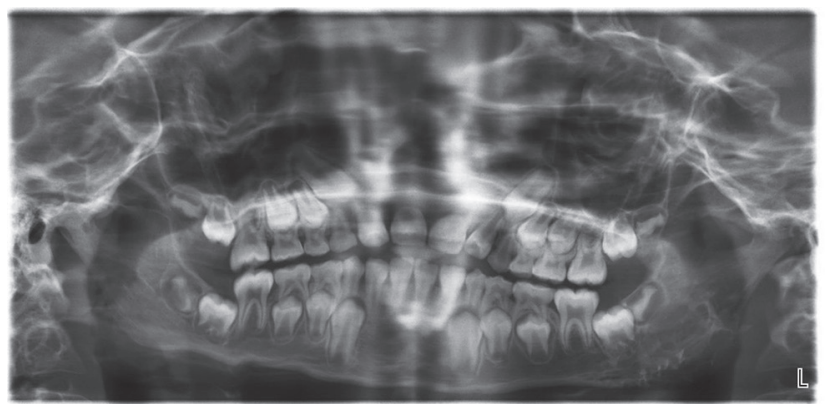

Fig. 1 Panoramic image showing multilocular radiolucency, with evidence of destruction of lower border, angle, and ascending ramus of the mandible.
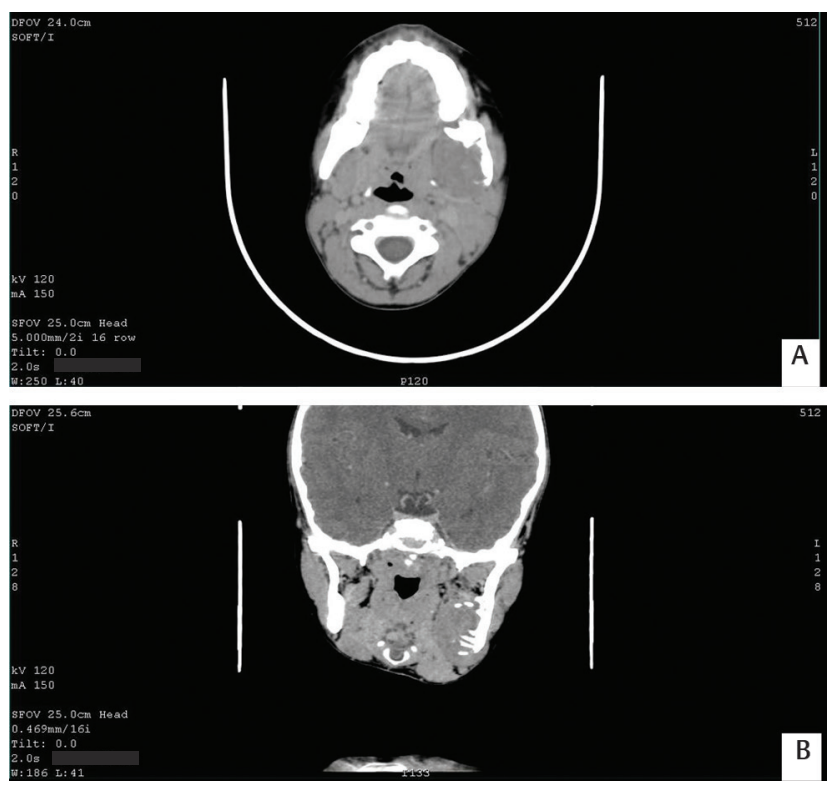

Fig. 2 (A) Axial section of the computed tomographic image showing an osteolytic hypodense lesion in the left angle of the mandible, with evidence of perforation and destruction of the cortical plates. (B) Coronal section of the computed tomographic image showing destruction of the cortical plates and the angle of the mandible.

Computed tomographic images showed an osteolytic hypodense lesion in the left angle of the mandible with evidence of perforation and destruction of the buccal and lingual cortical plate. The lesion has caused the destruction of the lower border of the mandible, the angle, and the ascending ramus of the mandible, with the advancing side the lesion positioned beyond the mandible causing pressure effect on the surrounding structures ( $\boldsymbol{- F i g}$. 2).

An incisional biopsy was performed. The hematoxylin and eosin-stained sections showed the proliferation of uniform fibroblasts in a collagenous stroma. The sections showed the presence of highly cellular condensed fibrous tissue along with elongated slender spindle cells with wavy and ovalshaped nuclei. There were occasional mitotic figures. Some areas were collagenous and some areas were myxoid. Slitlike vascular spaces were seen scattered throughout the connective tissue. The histopathologic features were suggestive of extra-abdominal desmoid fibromatosis ( - Fig. $\mathbf{3}$ ).
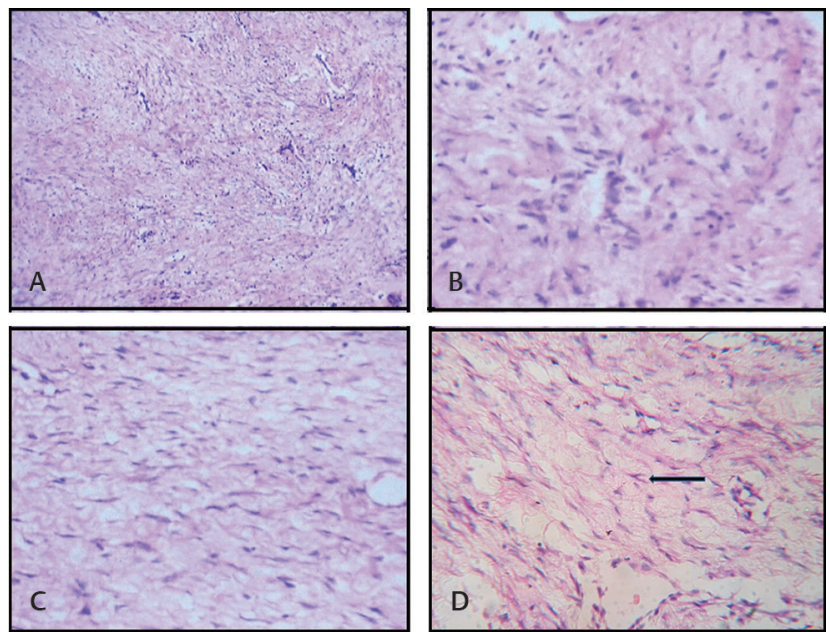

Fig. 3 (A) Photomicrograph showing proliferation of uniform fibroblasts in a collagenous stroma (H\&E stain; $\times 4$ magnification). (B-D) Photomicropgraph showing interlacing bundles of elongated spindle-shaped cells (H\&E stain; $\times 10$ magnification). H\&E, hematoxylin and eosin.

\section{Discussion}

Desmoid tumors are tumors of the fibrous tissue that are benign. These tumors most commonly occur in the abdominal walls of females who are of childbearing age. The most common location for extra-abdominal desmoid tumors is the shoulder and the upper limb. These are benign tumors showing no tendency for metastasis but are locally very aggressive. ${ }^{1}$ The desmoid tumor of the bone constitutes less than $1 \%$ of all bone tumors and approximately $0.3 \%$ of all benign osseous tumors. The mandible is the fourth most commonly affected site. In the mandible, the posterior part of the mandible, most often in the ramus-angle region, is the most affected. It is usually seen in the second and third decades of life with a slight female predilection. Treatment of choice for desmoplastic fibroma of bone is segmental resection. Segmental resection and a thorough curettage must be performed when the lesion recurs. Wide resection and a thorough "marginal" curettage is the favored method of treatment. Limited curettage usually leads to the continued growth of the tumor. ${ }^{2}$ Here we report a rare case of extra-abdominal desmoid fibromatosis in the mandible of a child.

\section{Conflict of Interest}

None declared.

\section{References}

1 Konikoth S, Bose T, Anupama IV, Yogidas R. Desmoplastic fibroma of the mandible-a rare benign tumor mimicking malignancy. J Indian Acad Oral Med Radiol. 2019;31:74-78

2 Guruprasad Y, Chauhan DS. Desmoplastic fibroma of mandible. Med J DY Patil Univ. 2015;8(2):254-257 